\title{
Practical improvements to the shotcreting process at Lisheen Mine with particular attention to the mix design and admixture usage
}

\author{
J.F. Talbot Vedanta Resources Lisheen Mine, Ireland \\ J. Burke Vedanta Resources Lisheen Mine, Ireland
}

\begin{abstract}
The Lisheen Mine is a 1.4 mtpa underground zinc and lead operation located in Co. Tipperary, Ireland. The mine commenced production in 1999. In the six years between 2004 and 2010 the amount of sprayed concrete increased from $4,600 \mathrm{~m}^{3}$ per year to over $11,000 \mathrm{~m}^{3}$ per year. In 2009 a series of inefficiencies, which had developed in the overall shotcreting process, were identified. These included overuse of accelerator, high rebound, poor machine availability, inadequate spraying technique and generally sub-optimal application which resulted in poor surface coverage, inadequate thickness and the need to re-spray.
\end{abstract}

In March 2010 a study was commenced to determine how to remedy these inefficiencies. The study focussed on the following areas:

- shotcrete management

- mechanical/maintenance issues

- quality assurance/mix design

- operator training.

The management element focussed mostly on planning and achieving maximum operator and spraying resources efficiency.

The mechanical aspect focussed on machine maintenance, availability, utilisation and downtime.

The quality assurance/mix design concentrated on a detailed view of all aspects of mix design with a view to improving initial set time, better cohesion and early strength development.

The operator training took the form of EFNARC sprayer training and certification which encouraged high quality application from the operators and adherence to the spraying procedure. In addition ground awareness and greater involvement by the shotcrete crew was used to motivate ownership of the operation.

As of November 2010 the efficiency of the spraying crew had improved by roughly 6\%. The overall machine availability had increased by roughly $15 \%$. Improvements in the mix design have given better adhesion, first pass thickness, better workability, and improved consistency in the mix and less rebound. The mine now has three qualified EFNARC sprayers who have demonstrated a measurable improvement in spraying technique.

This paper will outline the practical ways in which an operation can make significant improvements in its shotcrete process without disrupting day to day operations and ultimately produce a product that is of a very high standard.

\section{Introduction/shotcrete study 2010}

The Lisheen Mine is a $1.4 \mathrm{mtpa}$ underground zinc and lead operation located in Co. Tipperary, Ireland. The mine commenced production in 1999. In the six years between 2004 and 2010 the amount of sprayed 
concrete increased from 4,600 $\mathrm{m}^{3}$ per year to over $11,000 \mathrm{~m}^{3}$ per year. In 2009 a series of inefficiencies developing in the overall shotcreting process were identified. These included overuse of accelerator, high rebound, poor machine availability, inadequate spraying technique and generally sub-optimal application which resulted in poor surface coverage, inadequate thickness and the need to re-spray.

In March 2010 a study was commenced to determine how to remedy these inefficiencies. The study focussed on the following areas:

- shotcrete management

- mechanical/maintenance issues

- quality assurance/mix design

- operator training.

These four key areas of interest are shown in Table 1 with their subheadings.

Table 1 Key areas of interest for the study

\begin{tabular}{ccc|c}
\hline \multicolumn{3}{c}{ Shotcrete Study 2010 Primary Issues } \\
\hline Management & Mechanical & QA/QC & Training \\
Evaluation & Availability & Mix design & Operator availability \\
Requirement for shotcrete & Utilisation & Additives & Procedures \\
Heading availability & Downtime & Strength & Techniques \\
Priority & Servicing & Thickness & \\
Feedback & Operation & Adhesion & \\
& & Early strength & \\
\hline
\end{tabular}

\section{Shotcrete management}

In Lisheen Mine the term shotcrete management relates to the process and procedure in place from the time a request for shotcreting is received to the time the heading is handed back to the section shift boss for advancement. A heading is usually deemed to require shotcrete if the ground is identified as being sufficiently poor by the geotechnical engineer or personnel in the mine department experienced enough to assess the stability of a heading.

The judgements are usually made based on a combination of drilling information, visual assessments of the rock conditions, predicted ground behaviour, excavation usage and experience. At Lisheen there are various mix designs and thicknesses with a variety of applications based on the severity of the ground conditions. They are as follows:

- $50 \mathrm{~mm} \mathrm{S20} \mathrm{-} \mathrm{A} \mathrm{plain,} \mathrm{light} \mathrm{coat} \mathrm{of} \mathrm{shotcrete} \mathrm{for} \mathrm{the} \mathrm{purpose} \mathrm{of} \mathrm{sealing} \mathrm{off} \mathrm{friable} \mathrm{ground} \mathrm{so} \mathrm{that}$ further support (rebar, cables, mesh, straps) may be installed without further degradation in ground conditions.

- $75 \mathrm{~mm} \mathrm{S20} \mathrm{-} \mathrm{A} \mathrm{thicker} \mathrm{coat} \mathrm{of} \mathrm{plain} \mathrm{shotcrete} \mathrm{used} \mathrm{to} \mathrm{seal} \mathrm{areas} \mathrm{of} \mathrm{poorer} \mathrm{ground} \mathrm{conditions.} \mathrm{Due}$ to the better pumpability of the fibreless shotcrete it is also used in areas where an increased uphill gradient might hinder efficient spraying.

- $50 \mathrm{~mm} \mathrm{S35-A} \mathrm{polypropylene} \mathrm{fibre} \mathrm{mix} \mathrm{used} \mathrm{where} \mathrm{ground} \mathrm{conditions} \mathrm{are} \mathrm{blocky} \mathrm{with} \mathrm{wedges}$ developing and where longer term support capabilities are required.

- $75 \mathrm{~mm} \mathrm{S35-A} \mathrm{polypropylene} \mathrm{fibre} \mathrm{mix} \mathrm{used} \mathrm{in} \mathrm{the} \mathrm{poorest,} \mathrm{usually} \mathrm{soil-like} \mathrm{ground} \mathrm{conditions.}$ 
- $>75 \mathrm{~mm}$ S35 - Used primarily in long term underground construction such as crusher chambers or workshops.

The geotechnical engineer or mine department staff member will request one of the above mixes for a heading based on his/her assessment of the ground conditions and the heading is only accessible by the relevant support personnel until the job is completed. In early 2010 the procedure for shotcrete had lapsed and the process generally took the following steps as described in Figure 1.
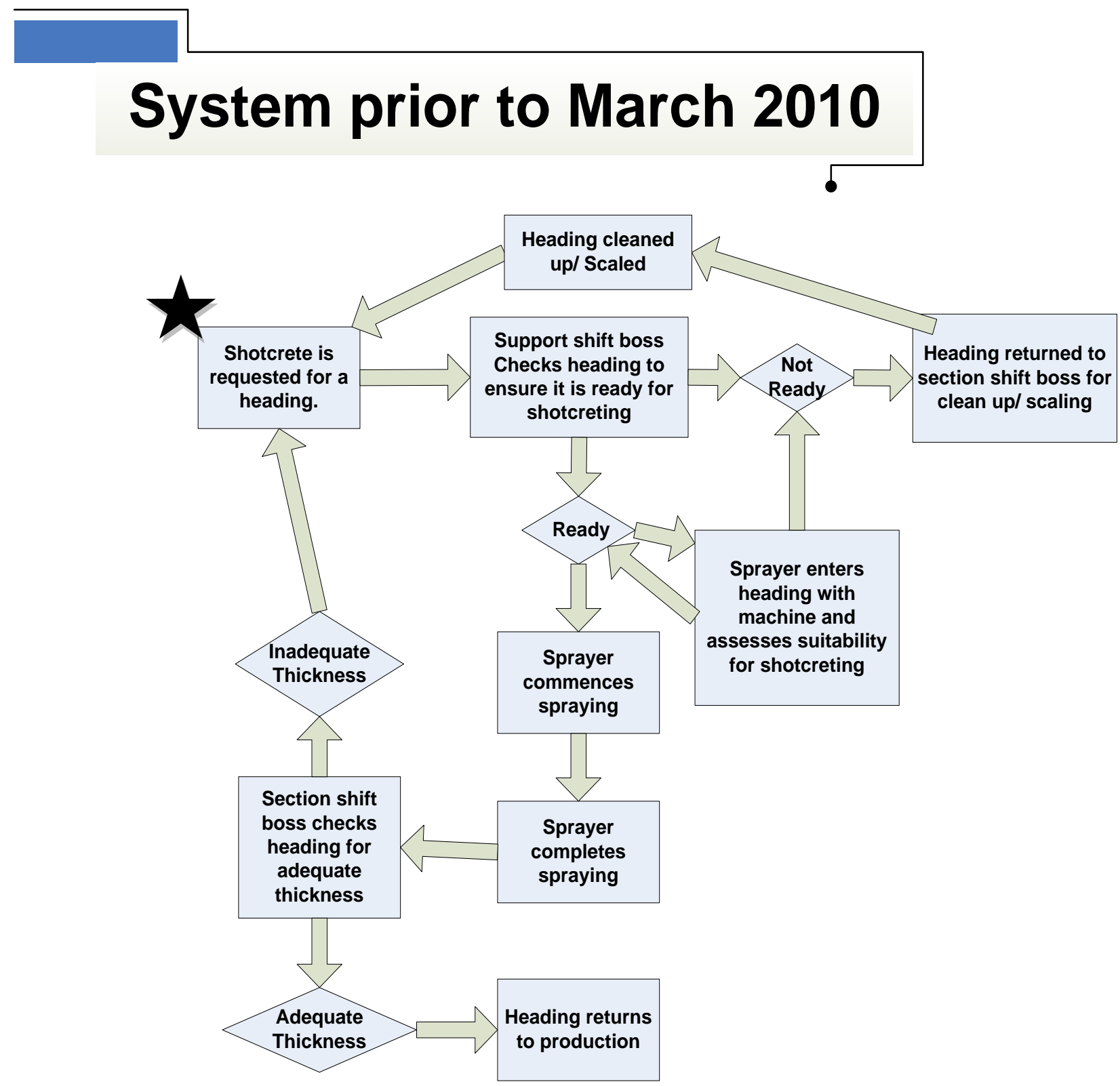

Figure 1 System of preparation of ends for shotcreting prior to March 2010

After completing a study in 2010, certain inefficiencies were highlighted. Although the system below was already in place to ensure that headings were ready for shotcrete it was not being enforced. This system was changed to the following procedure shown in Figure 2. 


\section{System after March 2010}

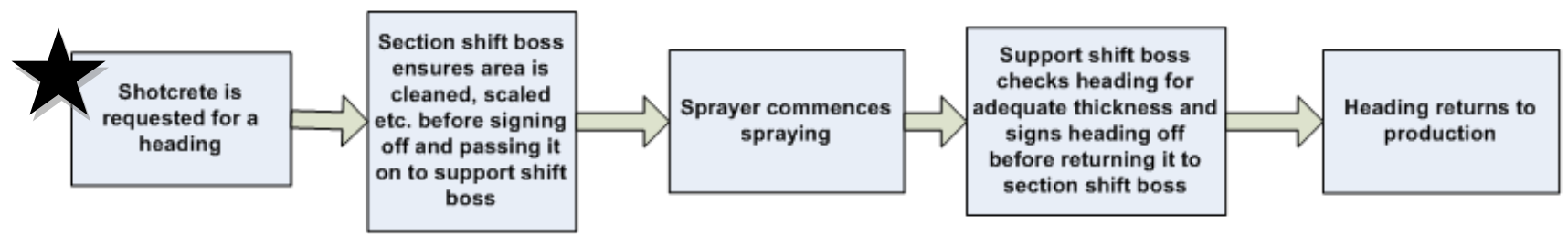

\section{Figure 2 System of preparation of ends for shotcreting after March 2010}

As the system above removes subjective assessments by those not directly responsible for the actions and returns the assessment to those whose responsibility it is to ensure those actions get done the new procedure is more streamlined and ultimately saves time.

Key to the whole process of shotcreting and ground support as a whole is operator feedback. Good feedback from shotcrete sprayers can provide details of ground conditions, mix design, quality of mixes, sprayability, pumpability, mechanical issues with the rig, and safety issues among other things. As such feedback is crucial in creating and maintaining an efficient shotcreting system at any operation.

Prior to the 2010 study some feedback from the operators was not being acted upon. This caused frustration from the operators with a resultant reduction in the level of feedback.

Although it is difficult for a geotechnical engineer to act upon every problem that may arise during multiple shifts of shotcreting, it is important to at least discuss these issues with the operator and explain what is being done to rectify the problem or why it cannot be done.

An example of this approach is shown in Figure 3. It shows a typical shotcrete operator report which in this case highlights three main issues. The first issue shows that the operator notes that the second heading sprayed, Main West 03X27, was wet and that a higher dose of accelerator was used (7\%) in order to compensate for this. The geotechnical engineer is now aware of an issue with ground conditions in the above heading and may request the use of cable bolts and mesh should it be required.

The second issue is the fact that three hours of spraying were lost at the start of shift due to a flat tyre on the delivery lorry from the batch plant. The geotechnical engineer can use this information to discuss the incident with the batch plant operator in order to ensure that in the event of a re-occurrence options for alternative deliveries are arranged.

The third issue highlighted is that in one of the headings the steep gradient, which had to be negotiated by the machines, means that it is difficult for the re-mix car to keep the hopper on the spraying rig full. There may be nothing the geotechnical engineer can do about this but the matter does warrant further discussion with the sprayer in order to see if some other solution can be found. This can be re-design of the heading making it less steep or the use of a hopper bin to deliver shotcrete to the sprayer. 


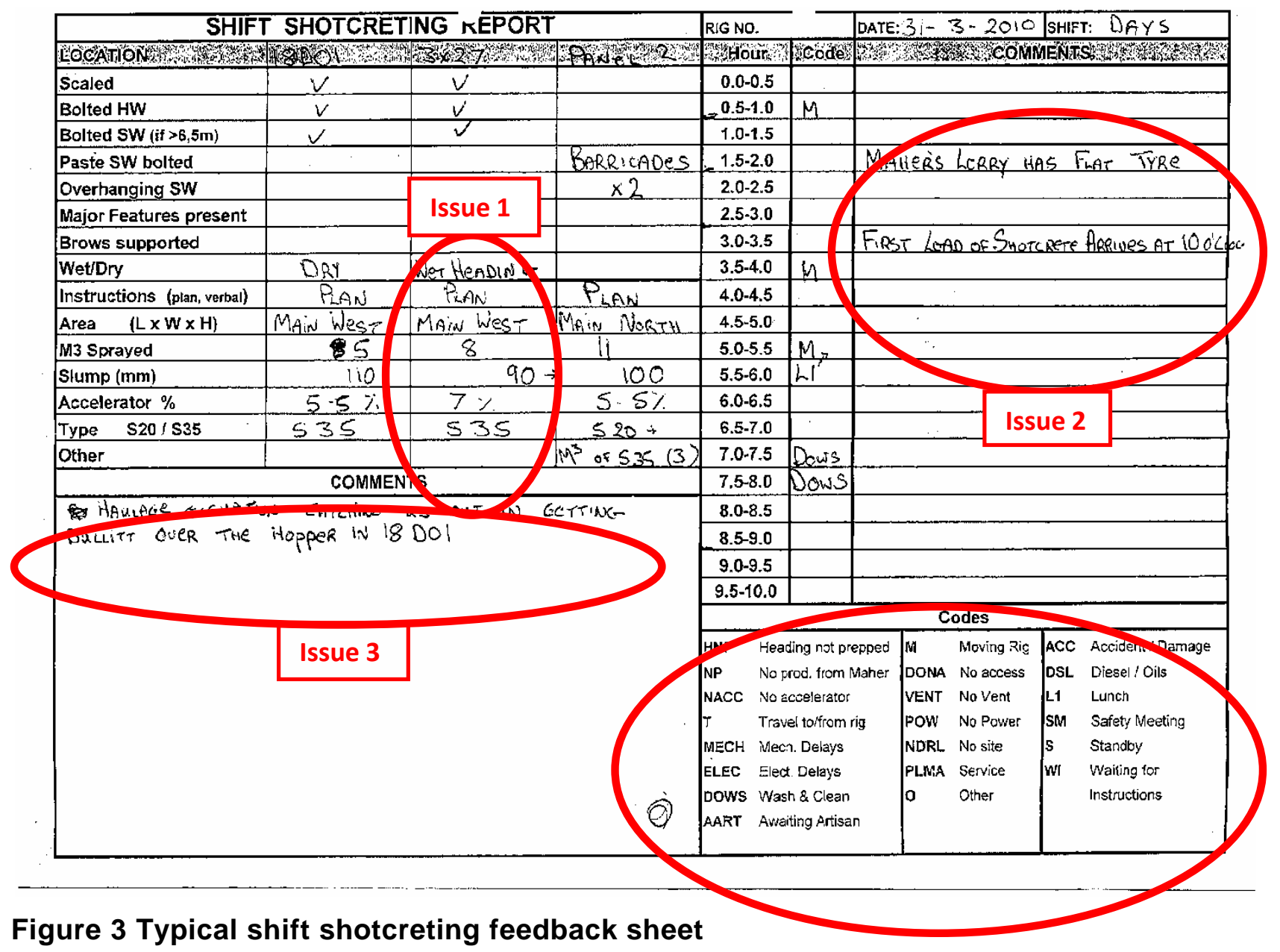

The codes system in Figure 3 also makes it possible to see what action was being taken by the shotcreting crew over the course of the shift and calculate utilisation figures based on this information. It was discovered, as is shown in Figure 4, that there was excessive mechanical downtime. The mechanical downtime is breakdowns only (not including routine maintenance) and accounts for $10 \%$ of the overall working time. Although it was known before the study that mechanical downtime was an issue, a figure of how much lost time was actually occurring as a result of breakdowns was now available and attempts could be made to lower the figure.

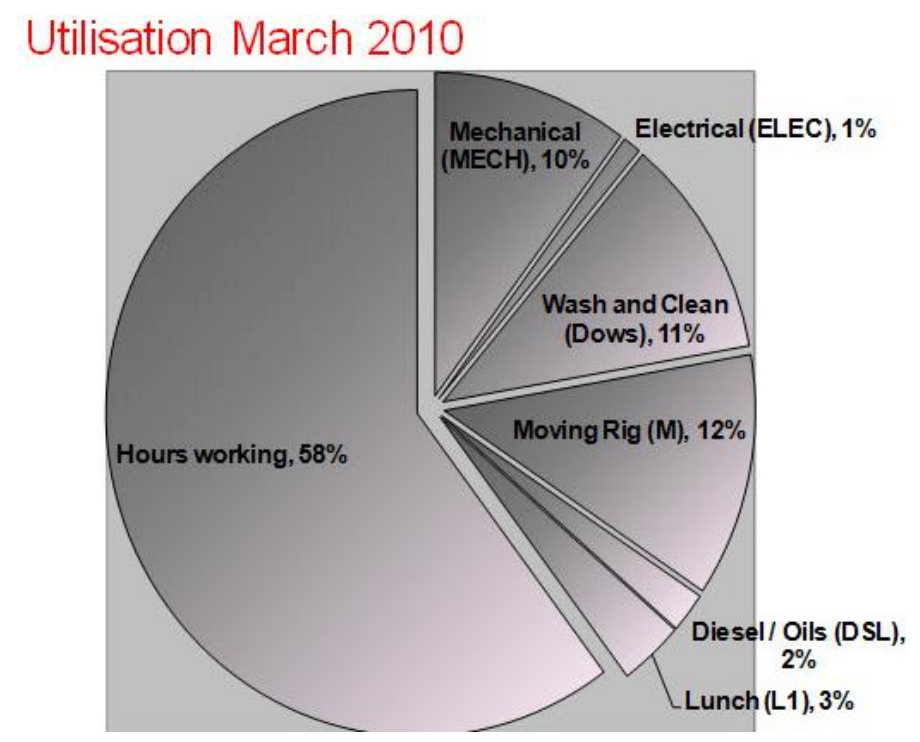

Figure 4 Utilisation March 2010 


\section{Mechanical}

The shotcreting fleet at Lisheen consists of:

- 2 x Normet Spraymec 6050 remote operated (Lisheen designation 127 and 128)

- 1 x Normet 1050M $5 \mathrm{~m}^{3}$ Transmixer (152)

- 1 x Fermel $5 \mathrm{~m}^{3}$ Transmixer and (151)

- 1 x Dux Utility Vehicle with $3 \mathrm{~m}^{3}$ Transmixer (053).

In order to reduce the amount of time spent on machine breakdowns a detailed study of machine availability was conducted. This, combined with feedback from the operators, allowed us to re-direct our maintenance resources in order to best deal with the mechanical issues that arise during the shotcreting process.

A study of machine availability for the month of March 2010 produced the results in Table 2. The assessment does not include routine weekly maintenance and is therefore related to breakdowns only.

\section{Table 2 Machine availability March 2010}

\begin{tabular}{ccc}
\hline \multicolumn{3}{c}{ Shotcrete Machine Availability March 2010} \\
Machine & Availability & Issues \\
\hline Normet Spraymec 127 & $78.6 \%$ & Slew cylinder, play on boom articulation \\
Normet Spraymec 128 & $54.3 \%$ & Ignition system and instrumentation \\
Normet 1050 Transmixer & $93.9 \%$ & Minor issues \\
Fermel Transmixer 151 & $0 \%$ & Rear door of mixer \\
Dux Transmixer 053 & $80.4 \%$ & Overheating and hydraulic system \\
\hline
\end{tabular}

A number of steps were taken to facilitate improvements to machine availability. Mobile plant fitters were informed that improvements in shotcrete machine availability were required. External help was also sought from the machine manufacturers in order to ensure that the routine machine maintenance was being conducted according to the manufacturer's specifications.

Operators were also given additional time at the end of shift to clean and maintain the rigs. In the past production pressure had sometimes meant that this phase of machine maintenance had been allowed to lapse. The procedure of allowing up to one hour at the end of shift for machine clean up and maintenance is now strictly adhered to and the benefits are clearly visible in the improved availability figures and the performance of the rigs.

Most importantly feedback from the machine operator was used to prioritise crucial maintenance issues with the rigs and the operator present for the entire service and maintenance process. As a result of this cooperation between operator and fitter a variety of long term issues affecting the machines availability or performance were highlighted and attempts were made to remedy them.

The combined efforts of operators and fitters were successful and by February 2011 the following improvements had been achieved as summarised in Table 3. 
Table 3 Machine availability February 2011

\begin{tabular}{ccc}
\hline \multicolumn{3}{c}{ Shotcrete Machine Availability Feb 2011} \\
Machine & Availability & Issues \\
\hline Normet Spraymec 127 & $84.9 \%$ & Play on boom \\
Normet Spraymec 128 & $89.5 \%$ & Minor issues \\
Normet 1050 Transmixer 152 & $96.3 \%$ & Minor issues \\
Fermel Transmixer 151 & $39.3 \%$ & Overheating \\
Dux Transmixer 053 & $81.7 \%$ & Minor issues \\
\hline
\end{tabular}

Although mechanical availability and time lost due to breakdowns still remains an issue, adequate systems for feedback and increased time allowed for routine maintenance have allowed improvements to be made. A comparison between Figure 4 (prior to improvements) and Figure 5 (post improvements) demonstrated the positive effect that the programme has had.

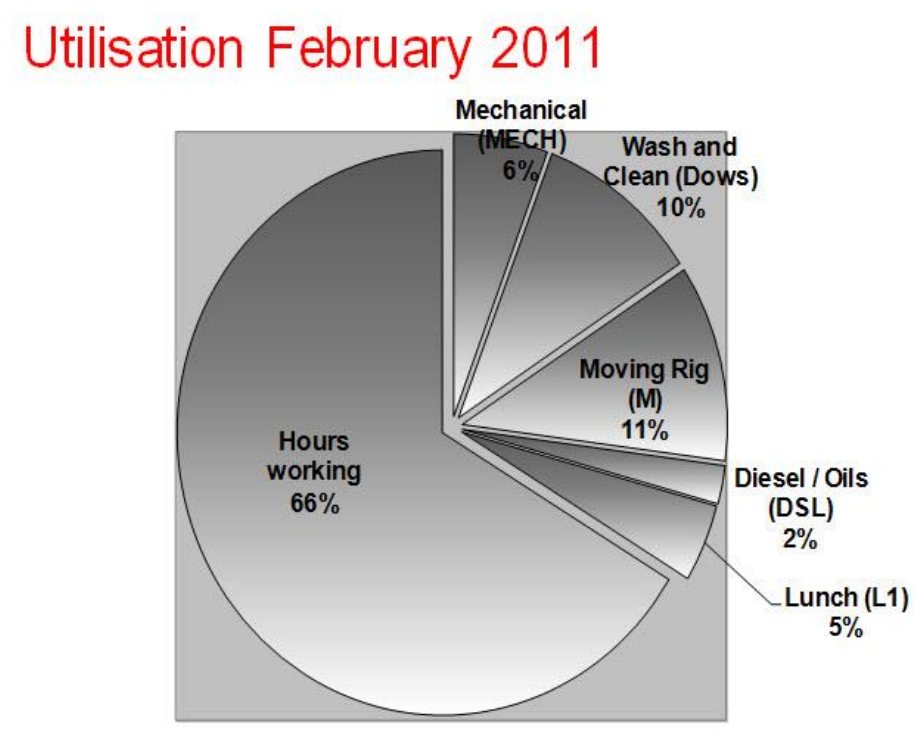

Figure 5 Utilisation February 2011

A reduction of $4 \%$ achieved in the mechanical downtime of the spraying rig and an overall increase in utilisation of $6 \%$ means a more efficient use of shotcreting resources at the mine.

\section{Quality control/mix design}

Prior to the start of the study there were a number of issues with the mix. Although strength development was not usually a problem, it proved difficult to achieve consistent mixes, pumpability, sprayability, and first-pass thickness. Proper storage and utilisation of the admixtures was also a constant problem.

When combined with the mechanical and shotcrete management issues it was sometimes difficult to determine which issue was having the biggest impact and thus exactly what was wrong with the mix.

Testing of the mix design commenced at the batch plant. Tests were conducted with various recipes of aggregates and admixture dosage to ensure that the mix coming to site was of the correct consistency, $\mathrm{w} / \mathrm{c}$ ratio and to ensure the batch plant operators were aware of what was required. Table 4 summarises the trial mixes conducted during March 2010.

Initially there was an addition of fines material at a ratio of 60:40 sand to fines as well as an increase in super-plasticiser. Ultimately the mix settled on was 80-20 sand to fines ratio with a super-plasticiser 
dosage of $2.88 \mathrm{I}$ per $\mathrm{m}^{3}$. This gave the mix more body and improved the strength development, better pumpability and better sprayability (Beauchamp, 2006).

Table 4 Trial mixes used during study (trial mixes per $\mathbf{m}^{3}$ )

\begin{tabular}{|c|c|c|c|c|c|c|c|c|}
\hline & $\begin{array}{l}\text { Sand } \\
\text { (kg) }\end{array}$ & $\begin{array}{l}\text { Limestone } \\
\text { Fines } \\
\text { (kg) }\end{array}$ & $\begin{array}{c}8 \text { mm Chip } \\
\text { (Import) } \\
\text { (kg) }\end{array}$ & $\begin{array}{c}8 \text { mm Chip } \\
\text { (Mahers) } \\
\text { (kg) }\end{array}$ & $\begin{array}{l}\text { OPC } \\
\text { (kg) }\end{array}$ & $\begin{array}{l}\text { Water } \\
\text { (I) }\end{array}$ & $\begin{array}{l}\text { Superplas } \\
\text { (I) }\end{array}$ & $\begin{array}{c}\text { Retarder } \\
\text { (I) }\end{array}$ \\
\hline Trial A & 1,100 & & 600 & & 420 & 190 & 2.41 & 1.75 \\
\hline Trial B & 660 & 440 & 600 & & 420 & 190 & 2.41 & 1.75 \\
\hline Trial C & 660 & 440 & 600 & & 420 & 190 & 4.82 & 1.75 \\
\hline Trial D & 660 & 440 & & 600 & 420 & 190 & 6.07 & 1.75 \\
\hline Trial E & 880 & 220 & & 600 & 420 & 190 & 4.67 & 1.75 \\
\hline $\begin{array}{l}\text { Trial E } \\
\text { (OLD } \\
\text { chip) }\end{array}$ & 880 & 220 & 600 & & 420 & 190 & 4.67 & 1.75 \\
\hline Trial F & 880 & 220 & 600 & & 420 & 190 & 4.67 & 2.52 \\
\hline Trial G & 990 & 110 & 600 & & 420 & 190 & 2.80 & 1.75 \\
\hline Trial H & 990 & 110 & 600 & & 420 & 190 & 2.41 & 1.75 \\
\hline Trial I & 990 & 110 & 600 & & 420 & 190 & 2.41 & 2.10 \\
\hline Trial J & 880 & 220 & 600 & & 420 & 190 & 2.41 & 2.10 \\
\hline Trial K & 880 & 220 & & 600 & 420 & 190 & 2.41 & 2.52 \\
\hline Trial L & 880 & 220 & & 600 & 420 & 190 & 2.88 & 2.52 \\
\hline Trial M & 935 & 165 & & 600 & 420 & 190 & 2.88 & 1.51 \\
\hline
\end{tabular}

Once a new mix design had been selected, it was necessary to ensure the mixes delivered from the batch plant consistently adhered to this mix design. This proved difficult as there were up to ten separate deliveries of eight $\mathrm{m}^{3}$ loads per day with sometimes up to three different delivery drivers batching the load.

Through consultation with the quarry manager and the delivery drivers it was possible to stress the importance of consistent mixes to all the shotcrete personnel. A system was introduced where the batch dockets from the plant were e-mailed directly to a member of the geotechnical department after each load in order to ensure the mix was as designed. An example of this is shown in Figure 6. 
Batch Data Report Moyne Page 1

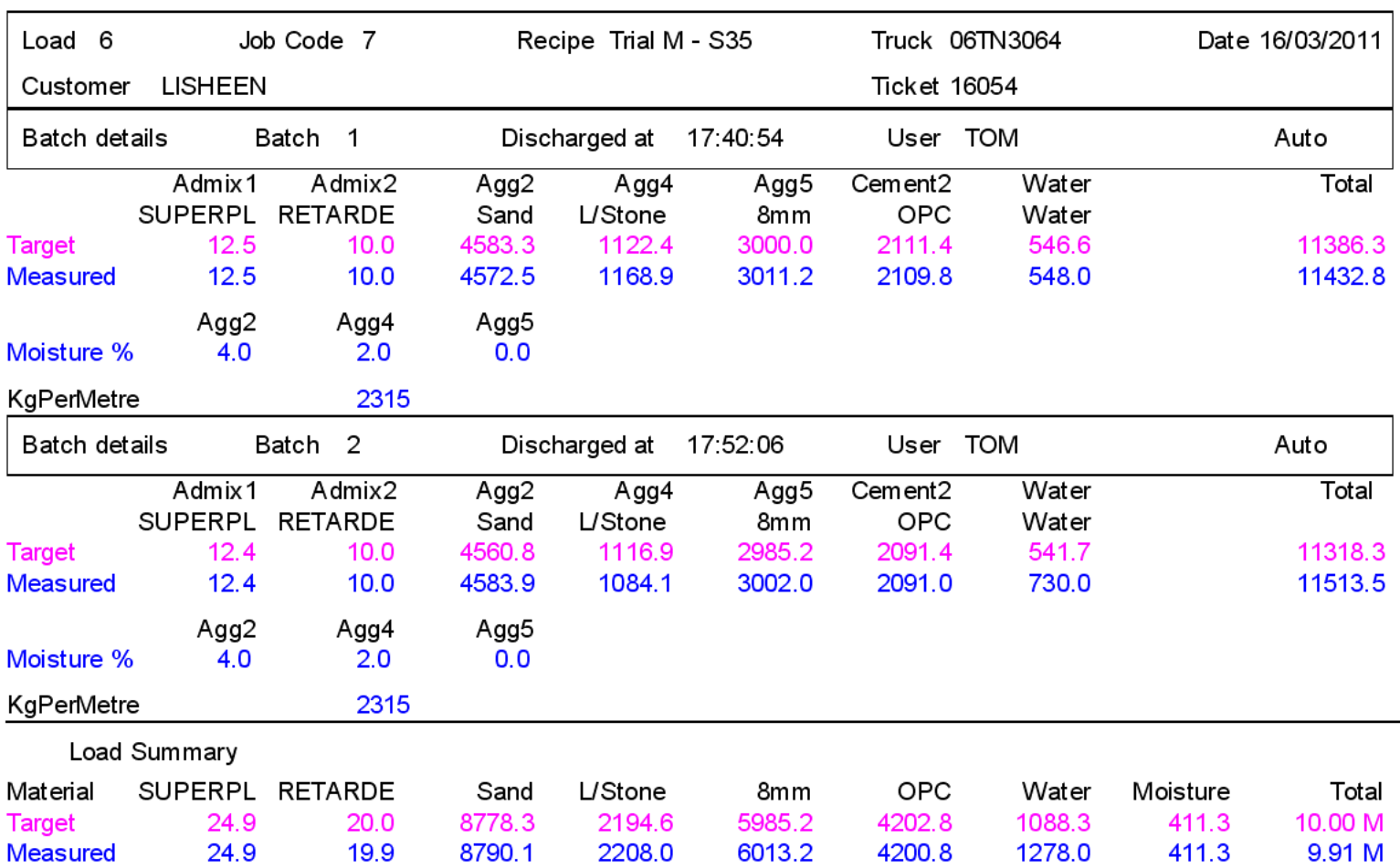

\section{Figure 6 Batch report from batching plant}

\section{$5 \quad$ Testing}

In parallel to the changes in mix design, testing was also being conducted to assess the improvement these changes made and their impact on the overall shotcreting process. However, commencing in April 2011, Lisheen began testing alternative admixtures. Up to March 2010 separate suppliers were used for accelerators, plasticisers and retarders. The plasticiser being used was a Type F plasticiser and the retarder was a construction chemical which seemed to inhibit the reaction between the cement and the accelerator. Alternative chemicals which complemented each other were tried and required a means of testing. The testing took the form of both field testing and laboratory testing.

The field testing consisted of a measure of workability (slump), open time (3-4 hours), sprayability (to minimise rig blockages and nozzle pulsation), rebound (minimise) and thickness (50 or $75 \mathrm{~mm}$ thickness in roof and sidewall).

The results of the field test showed an increase in slump to between 160 and $220 \mathrm{~mm}$. Prior to the study the slump varied from 100 to $180 \mathrm{~mm}$. The general increase in slump can be attributed to a slight increase in water-cement ratio and the switch to Type $G$ super-plasticiser.

Open time of roughly 3-4 hours was achieved with the correct dosage of hydration control/retarder. A longer open time is not required as the close proximity of the batching plant to the mine means that delivery to the site can be within half an hour, with arrival into the heading within the hour.

Sprayability was noted to be good but was more a function of fine tuning the mix design than admixture usage or dosage.

A wide variety of factors can influence the shotcrete thickness from ground conditions to nozzle spray distance to nozzle angle. The mine ultimately made a decision to change admixtures in November 2010. A comparison in thicknesses in the two months prior to changeover and the two months after changeover was made. The average roof and sidewall thickness are shown in Figure 7. 


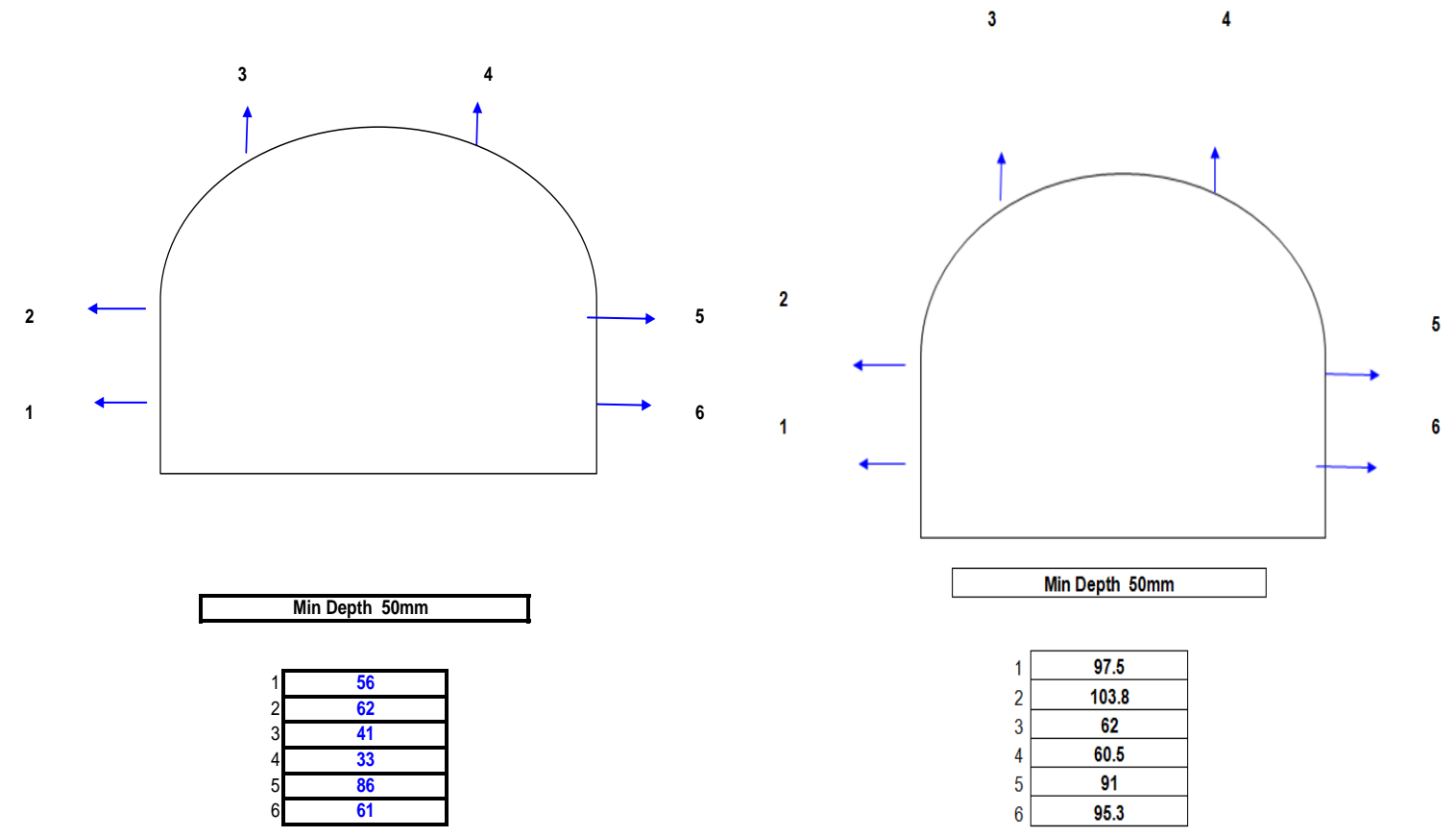

Thickness Pre-November 2011

Average roof thickness $37 \mathrm{~mm}$

Average sidewall thickness $66 \mathrm{~mm}$
Thickness Post-November 2011

Average roof thickness $61 \mathrm{~mm}$

Average sidewall thickness $97 \mathrm{~mm}$

Figure 7 Average roof thicknesses pre and post-November 2011

Figure 7 demonstrates the success that was achieved with a change in mix design and admixture trials. However, field tests had to be verified in the laboratory to ensure strength had not been sacrificed as a result.

Lisheen conducted a number of round and square panel tests in November 2010. The test quantified the strength of the new mix design with different admixtures. Figure 8 shows the results of round panel tests conducted after 28 days curing time. The peak strength and residual strengths after $40 \mathrm{~mm}$ deflection are highlighted in the graph ( $25.5 \mathrm{kN}$ after $2.93 \mathrm{~mm}$ deflection). 


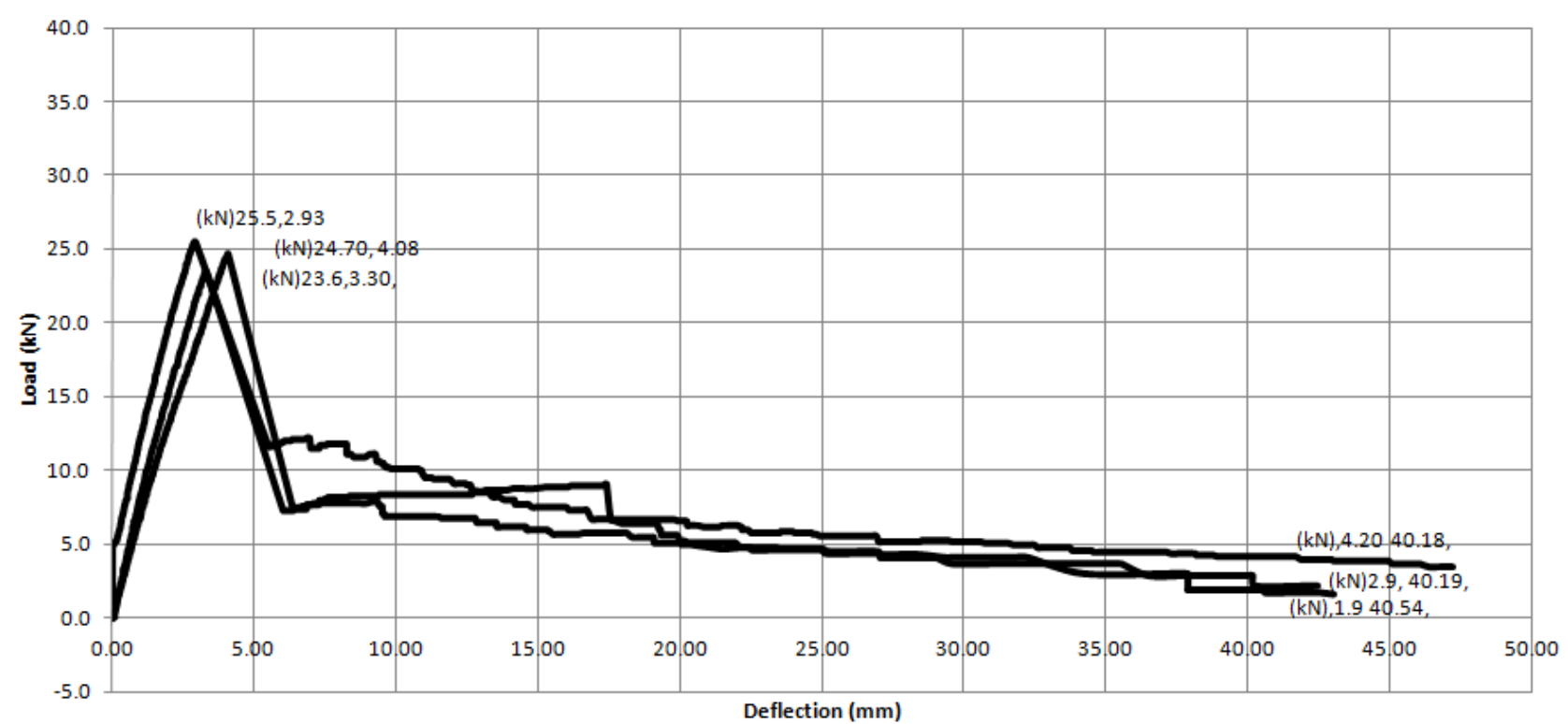

Figure 8 Round panel load versus deflection

Figure 9 shows the energy absorption for square panel tests conducted after 28 days setting time. The maximum is $306.48 \mathrm{j}$ after $40 \mathrm{~mm}$ deflection. Previous testing conducted by University College Dublin in 2005 had shown a peak load of $20.72 \mathrm{kN}$ after $2.55 \mathrm{~mm}$ deflection and energy absorption of $211.02 \mathrm{j}$ after $40.43 \mathrm{~mm}$ deflection.

Energy absorbtion (Joules)

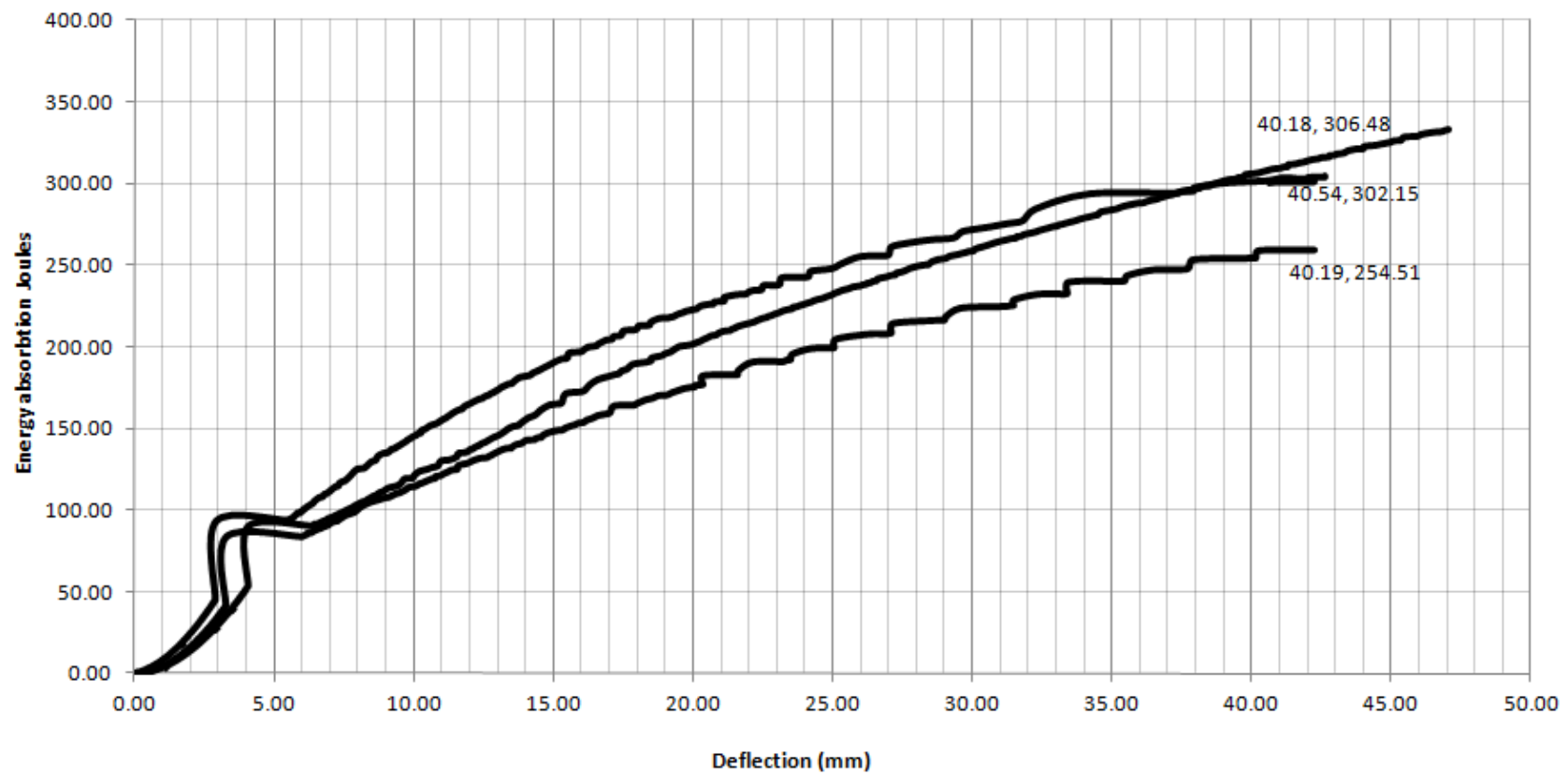

Figure 9 Energy absorption (joules) for square panel test

The square panel testing also proved useful and from these results it was concluded which admixtures were suitable and also confirmed that the changes in admixtures had a positive influence on strengths and energy absorption. 
Further laboratory tests were carried out in order to determine the admixture reactivity, the initial and final set by Vicat needle method (Melbye, 2006), and the temperature generation post accelerator reaction. Figure 10 shows a picture of the laboratory set-up which allowed the above to be measured.

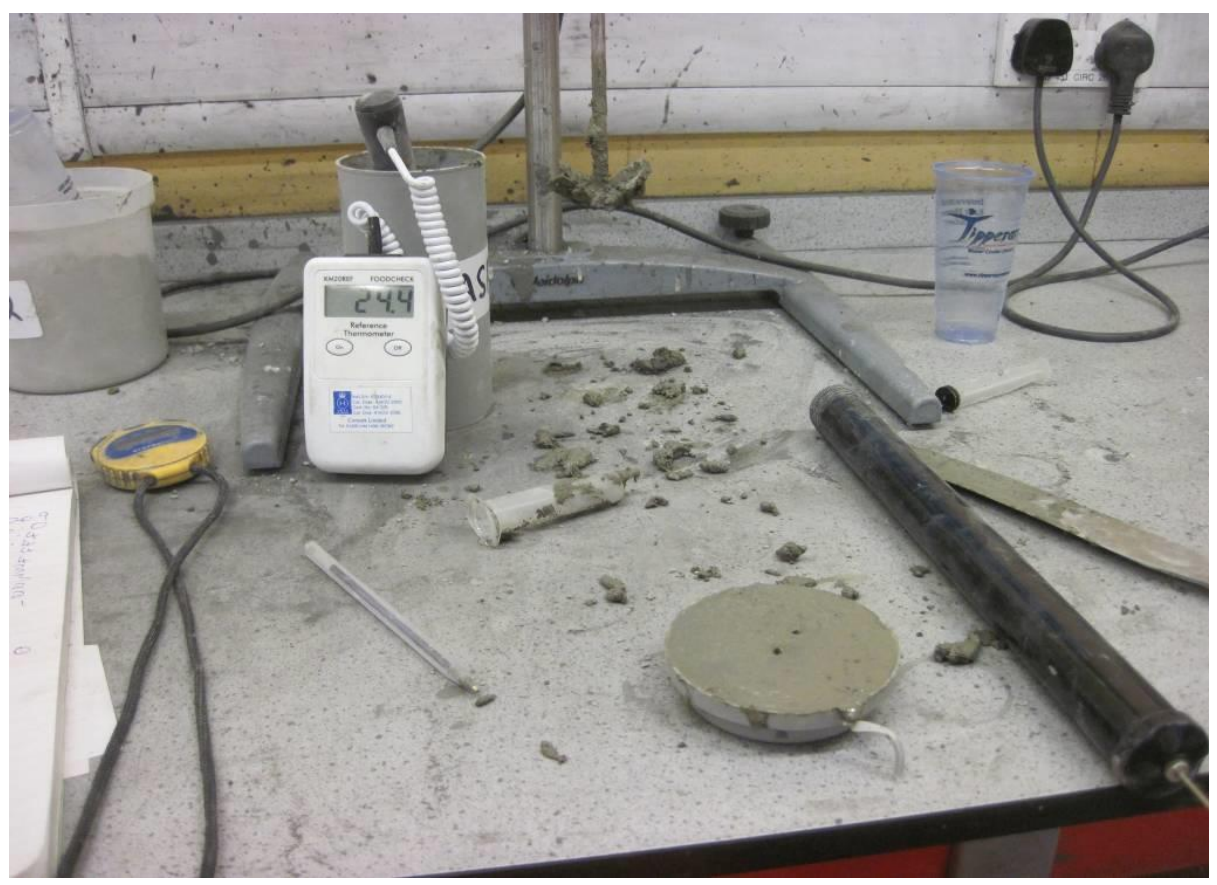

\section{Figure 10 Vicat/temperature test set-up}

The mixes used in the test were as follows:

\section{Table 5 Mix designs for Vicat tests}

\begin{tabular}{ccccc}
\hline & Mix A (kg) & \% pwc & Mix B (kg) & \% pwc \\
\hline Cem 2 OPC & 0.24 & & 0.3 & \\
Water & 0.1 & & 0.1 & \\
Sand & 0.3 & & 0 & \\
& & & .03 & \\
Fines & 0.05 & & 0.05 & \\
Hyd cont/retarder & 0.000856 & 0.36 & 0.000856 & 0.29 \\
Plasticiser & 0.001712 & 0.71 & 0.001712 & 0.57 \\
Accelerator A & 0.0147 & 6.13 & 0.0154 & 5.13 \\
Accelerator B & 0.0150 & 6.26 & 0.0157 & 5.24 \\
\hline
\end{tabular}

After mixing the grout as per the mix design in Table 5 accelerator was added the specified dosage by syringe and mixed with the grout. A portion of the mix was then added to a small dish and tested using a Vicat needle while the rest of the mix remained in the mixing pot with a temperature probe inserted in order to monitor the temperature generation. The experiment was conducted a number of times for both mixes using a combination of admixtures. Figures 11 and 12 show the temperature generation with respect to time and also shows the points at which initial setting and final setting occurred for each combination of admixtures. 
Temperature Generation Mix A

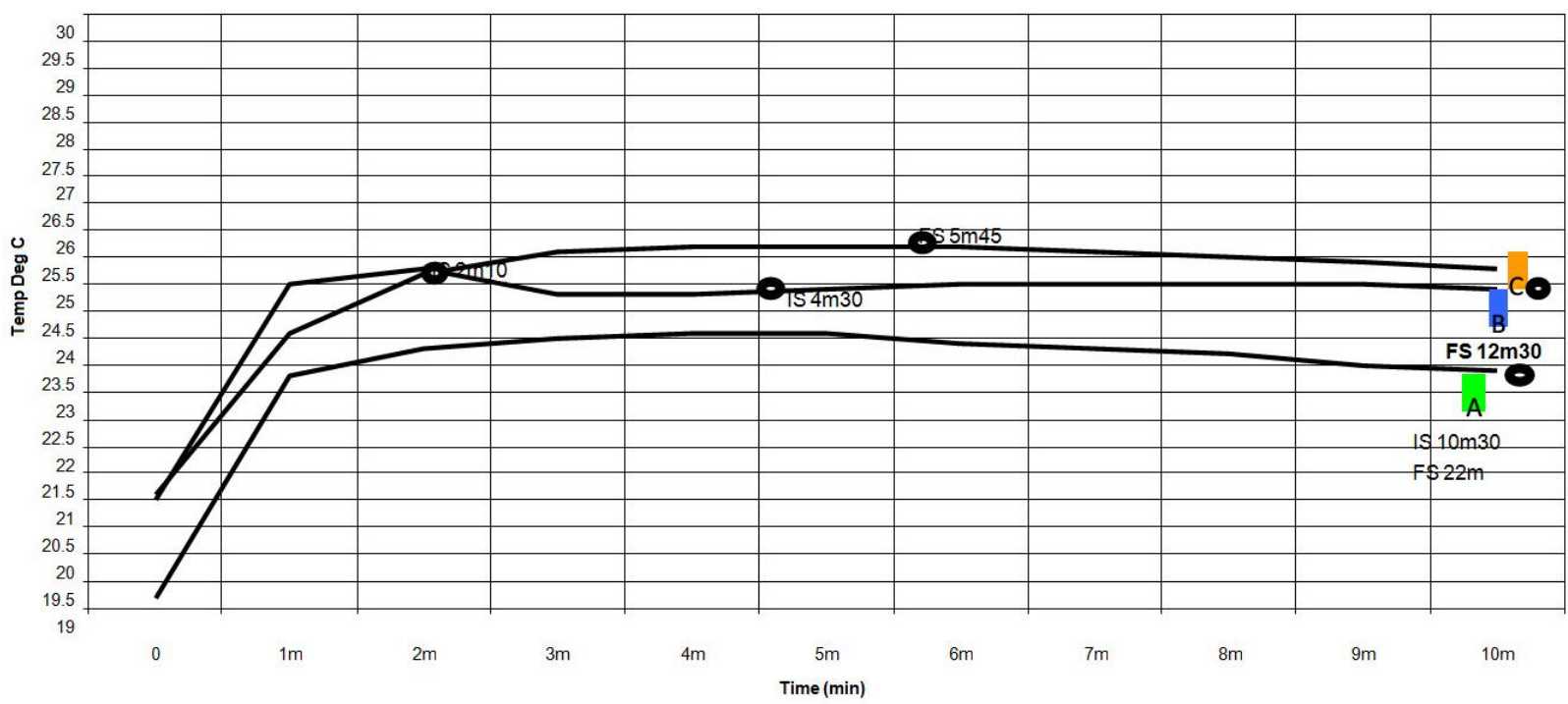

Figure 11 Temperature generation and setting time with respect to time Mix A

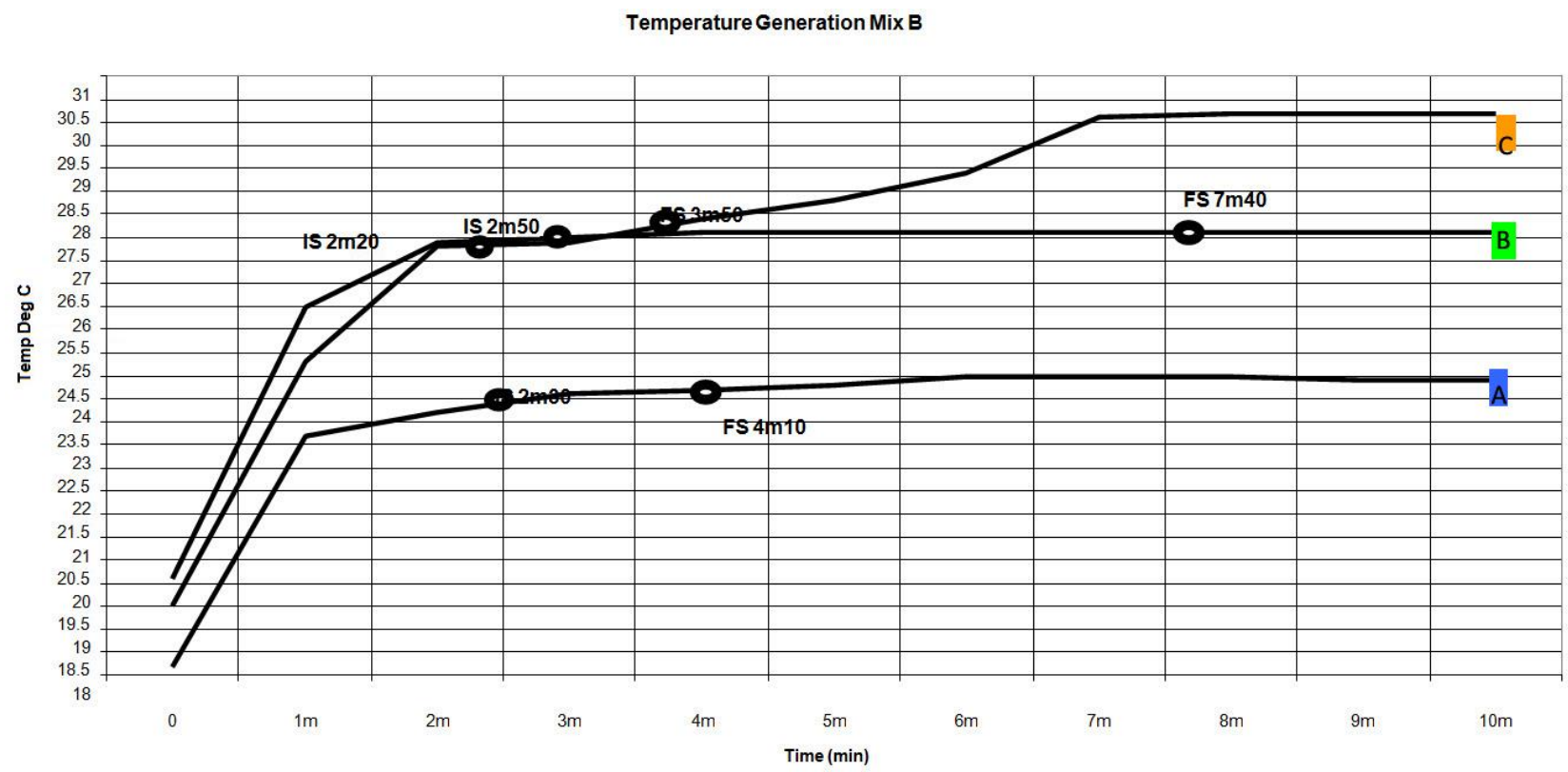

Figure 12 Temperature generation and setting time with respect to time Mix B

The worst performing combination of chemicals was the line highlighted in green which had an initial set time of 10 mins 30 secs. This combination also had the least temperature generation.

Line A in Figure 12 shows the worst performing combination of admixtures with respect to temperature generation. However, the initial and final set is still quite short. The green (Line B) combination of admixtures has good temperature generation but a longer initial and final set time. This combination of admixtures was the combination used at Lisheen prior to 2010. The tests showed that there were significant gains to be made in early set time from switching to a different combination of admixtures.

Another issue which arose as a result of the study was the improper storage of admixtures. The accelerator storage system in place prior to March 2010 provided insulation against severe fluctuations in temperature. It did not however provide any agitation and material was separating or clumping. The system now in place provides automatic heat and agitation for the accelerator tanks as well as easy, safe storage and access for filling. 


\section{$6 \quad$ Training}

As the mine operates under a shift pattern, multiple qualified sprayers must be available to operate the spraying rigs and associated machinery. The March 2010 study identified the need for further training of sprayers to bring the skill and knowledge level to a world class standard. The study highlighted a number of areas where our spraying technique was deficient.

A key issue which arose was that operators were not using the remote control unit for spraying in every instance. This limited the sprayer's field of vision and resulted in poor application.

It was also found that the majority of shotcreting personnel were not involved in ensuring quality control of the concrete from the moment it arrived onsite. Thus remixer drivers were sometime unable to ensure that the best mix was delivered to the headings for spraying.

It was noted also that operators were unaware of the high importance of spraying with the correct nozzle distance or angle and that shotcrete personnel required more assistance in the field of machine maintenance (EFNARC, 2009).

In order to remedy the issues with operator training an external consultant was brought in to perform EFNARC nozzleman training with the three operators who had the required experience for certification. More general training was also given to other shotcrete operators, supervisors and maintenance personnel.

The process was run over a number of visits and by the end of the training there were three EFNARC certified nozzlemen as well as three further certified operators and a general increase in awareness of every facet of the shotcrete process, particularly the mechanical and mix design aspects.

The study undertaken in March 2010 took a holistic practical look at every aspect of the shotcreting process. When it was finished improvements had been made in the efficiencies of shotcrete management and a system of greater feedback gave everyone a better understanding of common problems met by operators and managers alike.

Improvements in maintenance allowed monitoring of machine conditions in the equipment fleet and attempted to improve routine maintenance in order to avoid time lost due to breakdowns.

A comprehensive study of the mix design and admixture type and dosage has resulted in a consistent mix which performs well in most ground conditions encountered. Savings have been made due to less rebound and less admixture wastage (due to better storage) whilst the improved shotcrete also provides a safer environment for all personnel underground.

The additional training and EFNARC nozzleman certification has improved the application of shotcrete throughout the mine and has raised the standard of professionalism amongst the shotcrete personnel who are now familiar with every aspect of the process.

Overall, the review of shotcrete at Lisheen Mine has provided a better, less costly product which performs according to the best international standard. The mine now has another weapon in its support arsenal allowing it to better cope with the variable ground conditions encountered on a daily basis.

\section{Acknowledgement}

The author thanks the management and staff at Lisheen Mine for allowing this exercise to be conducted. The author also thanks his colleagues for helping in the completion of it, particularly Joe Burke, Owen O'Brien and Padraig Barrett.

\section{References}

Beauchamp, L.A. (2006) Ground Support Manual, Mines and Aggregates Safety and Health Association, Ontario, Canada. EFNARC (2009) Efnarc nozzleman certification scheme course notes, EFNARC.

Melbye, T. (2006) Sprayed Concrete for Rock Support, UGC International User Manual, Switzerland. 